\title{
Tropospheric carbon monoxide concentrations and variability on Venus from Venus Express/VIRTIS-M observations
}

Constantine C. C. Tsang, ${ }^{1}$ Patrick G. J. Irwin, ${ }^{1}$ Colin F. Wilson, ${ }^{1}$ Fredric W. Taylor, ${ }^{1}$ Chris Lee, ${ }^{2}$ Remco de Kok, ${ }^{1}$ Pierre Drossart, ${ }^{3}$ Giuseppe Piccioni, ${ }^{4}$ Bruno Bezard, ${ }^{3}$ and Simon Calcutt ${ }^{1}$

Received 26 January 2008; revised 10 June 2008; accepted 25 June 2008; published 1 October 2008.

[1] We present nightside observations of tropospheric carbon monoxide in the southern hemisphere near the $35 \mathrm{~km}$ height level, the first from Venus Express/Visible and Infrared Thermal Imaging Spectrometer (VIRTIS)-M-IR.

VIRTIS-M data from 2.18 to $2.50 \mu \mathrm{m}$, with a spectral resolution of $10 \mathrm{~nm}$, were used in the analysis. Spectra were binned, with widths ranging from 5 to 30 spatial pixels, to increase the signal-to-noise ratio, while at the same time reducing the total number of retrievals required for complete spatial coverage. We calculate the mean abundance for carbon monoxide at the equator to be $23 \pm 2 \mathrm{ppm}$. The CO concentration increases toward the poles, peaking at a latitude of approximately $60^{\circ} \mathrm{S}$, with a mean value of $32 \pm 2 \mathrm{ppm}$. This $40 \%$ equator-to-pole increase is consistent with the values found by Collard et al. (1993) from Galileo/NIMS observations. Observations suggest an overturning in this CO gradient past $60^{\circ} \mathrm{S}$, declining to abundances seen in the midlatitudes. Zonal variability in this peak value has also been measured, varying on the order of $10 \%(\sim 3 \mathrm{ppm})$ at different longitudes on a latitude circle. The zonal variability of the $\mathrm{CO}$ abundance has possible implications for the lifetime of $\mathrm{CO}$ and its dynamics in the troposphere. This work has definitively established a distribution of tropospheric $\mathrm{CO}$, which is consistent with a Hadley cell circulation, and placed limits on the latitudinal extent of the cell.

Citation: Tsang, C. C. C., P. G. J. Irwin, C. F. Wilson, F. W. Taylor, C. Lee, R. de Kok, P. Drossart, G. Piccioni, B. Bezard, and S. Calcutt (2008), Tropospheric carbon monoxide concentrations and variability on Venus from Venus Express/VIRTIS-M observations, J. Geophys. Res., 113, E00B08, doi:10.1029/2008JE003089.

\section{Introduction}

\subsection{Past Observations of Tropospheric CO}

[2] The near-infrared thermal emissions were discovered by Allen and Crawford [1984] and were shown to be emanating from the deep troposphere of Venus by radiative transfer modeling by Kamp et al. [1988] and Bezard et al. [1990]. These emissions, spanning spectral wavelengths from 1.01 to $2.50 \mu \mathrm{m}$, are attenuated as they pass through the cloud layer, so the radiance observed from space is sensitive to changes in the total cloud optical depths. It is also sensitive to abundances of minor species, namely $\mathrm{CO}, \mathrm{H}_{2} \mathrm{O}$, $\mathrm{HDO}, \mathrm{OCS}, \mathrm{SO}_{2}, \mathrm{HF}$, and $\mathrm{HCl}$, at altitudes ranging from the surface to the base of the cloud layer at $45 \mathrm{~km}$. A compre-

\footnotetext{
${ }^{1}$ Atmospheric, Oceanic and Planetary Physics, Clarendon Laboratory, Department of Physics, University of Oxford, Oxford, UK.

${ }^{2}$ Geophysics and Planetary Sciences, California Institute of Technology, Pasadena, California, USA.

${ }^{3}$ LESIA, Observatoire de Paris, Meudon, France.

${ }^{4}$ INAF-IASF, Rome, Italy.
}

Copyright 2008 by the American Geophysical Union. 0148-0227/08/2008JE003089\$09.00 hensive review of the near-infrared windows can be found in the work of Taylor et al. [1997] and Baines et al. [2006].

[3] While Kamp et al. [1988] were the first to propose retrieving abundances of these minor species, it was the subsequent observations by Bezard et al. [1990] and Pollack et al. [1993] using the Canada France Hawaii Telescope, who first measured the $\mathrm{CO}$ abundance in the troposphere, estimating mean values at $36 \mathrm{~km}$ of $40 \mathrm{ppm}$ and $23 \pm 5 \mathrm{ppm}$, respectively. Pollack et al. [1993] also retrieved a CO vertical profile, with increases of $1.20 \pm 0.45 \mathrm{ppm} \mathrm{km}^{-1}$ increasing with height. At approximately the same time, the Galileo spacecraft flew past Venus on its trajectory to Jupiter. Onboard, the NIMS imaging spectrometer took the first images from space of the nightside of Venus, most notably at the wavelengths of 1.74 and $2.30 \mu \mathrm{m}$.

[4] Collard et al. [1993] measured the latitude distribution of CO from the Galileo/NIMS VJBAR data set. Rather than using a spectral fitting technique, Collard et al. [1993] positively detected a latitude $\mathrm{CO}$ gradient using a method of ratios of spectra at two different wavelengths. It was shown that a $\mathrm{CO}$ meridional gradient exists in the lower atmosphere, with an enhancement mainly poleward of $47^{\circ} \mathrm{N}$. This work 
remained unverified until only relatively recently, when Marcq et al. [2005, 2006] using the NASA/IRTF/SpeX, observed the same $\mathrm{CO}$ gradient from ground-based highresolution nightside spectra. From this analysis, a lower limit for the equator-to-pole $\mathrm{CO}$ gradient was found to increase by approximately $15 \%$ from the equator to $40^{\circ} \mathrm{N} / \mathrm{S}$, less than the $35 \%$ increase found by Collard et al. [1993]. While this is a lower gradient, it does not cover the high latitudes covered by Galileo/NIMS. In addition, neither Collard et al. [1993] nor Marcq et al. [2006] were able to measure any zonal distribution or variability of $\mathrm{CO}$ because of the limited horizontal and temporal sampling of their observations.

\subsection{CO as a Dynamical Tracer}

[5] Gierasch [1975] postulated that a mean meridional circulation would exist in the Venus atmosphere, transporting momentum from the equator to the poles. This was verified by the in situ measurements of meridional winds by the Pioneer large and small probes [Counselman et al., 1980]. Images of Venus' dayside in the UV reveal cloud features at $65-75 \mathrm{~km}$ altitude; tracking these features with potential vorticity data revealed meridional wind speeds of $>10 \mathrm{~m} \mathrm{~s}^{-1}$ [Limaye, 2007] at this altitude. Nightside images of Venus at 1.7 and $2.3 \mu \mathrm{m}$ exhibit contrast because of variability in the lower cloud layer at $50 \mathrm{~km}$. Analysis of Galileo/NIMS [Carlson et al., 1991] found that the motion of the features indicated that meridional flow is still poleward at this altitude. This would indicate the Hadley cell extended to a depth of at least this altitude. It is this Hadley cell circulation which maintains the midlatitude jets [Lee et al., 2007], which in turn support the super-rotation, with high zonal wind speeds. In addition, because the Hadley cell is transporting angular momentum toward the poles, it may also be responsible for maintaining the polar vortex seen from a latitude of $70^{\circ}$ poleward. There are strong indications, from both observations and general circulation models (GCM), that this equator-to-pole circulation exists in both hemispheres. However, both the vertical and latitudinal extent of the Hadley cells are yet to be fully understood. Outstanding questions include how far in latitude do the Hadley cells extend, how deep in altitude they go, are the southern and northern hemisphere cells symmetric about the equator, and are there any timedependent horizontal variations of these cells.

[6] The tropospheric $\mathrm{CO}$ enhancement was interpreted by Taylor [1995] to be caused by the descending arm of the Hadley cell, bringing down $\mathrm{CO}$ from above the cloud tops where the photolysis of $\mathrm{CO}_{2}$ by $\mathrm{UV}$, with an energetic threshold for photo-dissociation near $224 \mathrm{~nm}$ [Von Zahn et al., 1983], creates $\mathrm{CO}$ (noting that the $\mathrm{CO}_{2}$ cross section is dominated by Rayleigh scattering longward of $205 \mathrm{~nm}$ [Shemansky, 1972; Karaiskou et al., 2004]). As CO descends, it is believed to be converted to OCS and $\mathrm{CO}_{2}$ [Krasnopolsky, 2007; Fegley et al., 1997; Hong and Fegley, 1997; Y. Yung et al., Modeling the distribution of OCS in the lower atmosphere of Venus, submitted to Journal of Geophysical Research, 2008]. It is therefore possible to use $\mathrm{CO}$ as a dynamical tracer, which is entrained by the circulation of the lower atmosphere. This would not only provide mean abundances of $\mathrm{CO}$ in the lower atmosphere, but also provide information on the size and variability of the Hadley cell in the deep atmosphere.

\section{Venus Express/VIRTIS-M Observations}

[7] Venus Express entered Venus orbit in April 2006. Onboard are seven science instruments devoted to observing the atmosphere and surface of Venus from UV to infrared and radio wavelengths. Visible and Infrared Thermal Imaging Spectrometer (VIRTIS), which is also flying on the Rosetta mission [Coradini et al., 1998], is one of these instruments. Covering wavelengths from 0.27 to $5.19 \mu \mathrm{m}$, VIRTIS is divided into two subsystems; the nonimaging $\mathrm{H}$ channel covering the spectral ranges from 1.84 to $4.99 \mu \mathrm{m}$, with a spectral resolution of $1 \mathrm{~nm}$, and the imaging $M$ channel, which is further divided into two channels. One channel, viewing in the UV and visible wavelengths, is named $\mathrm{M}-\mathrm{V}$ is, while the 1.05 to $5.19 \mu \mathrm{m}$ spectral region is sounded by the M-IR channel. The spectral resolution of VIRTIS-M is approximately $2 \mathrm{~nm}$ and $10 \mathrm{~nm}$ for the VIS and IR sub-channels, respectively. In this analysis, we will be using data from the VIRTIS-M-IR subsystem only. A comprehensive review of VIRTIS is given by Drossart et al. [2007] and Piccioni et al. [2007].

[8] While the ability of VIRTIS-H to obtain higher resolution spectra has obvious advantages, such as better retrieval of the absolute abundances of minor species as well as their vertical distribution, the multispectral imaging capabilities of VIRTIS-M makes it uniquely able to map global-scale properties such as cloud opacity and wind field measurements. It is this capability not only to measure the global-scale values of minor species, but also to do so as a function of time, which we intend to take advantage of. Indeed, this has always been one of the key measurements to be made with VIRTIS [Baines et al., 2006].

[9] The single linear array of VIRTIS-M has an instantaneous field of view of $0.25 \times 64 \mathrm{mrad}$, divided into 256 spatial pixels. At an apogee of $66,000 \mathrm{~km}$, this instantaneous field of view spans one third of the diameter of Venus. Using a scan mirror, with 256 step positions, the field of view expands to $64 \times 64 \mathrm{mrad}$. Therefore, at apogee, a full image of the Venus disc is created when nine images are taken sequentially to create a $3 \times 3$ mosaic image.

[10] Table 1 shows the list of observations used in this analysis; two orbit insertion observations, CIOB00 taken on 12 April 2006, and CIOB03 on 16 April 2006, and two nominal orbit observations in orbit number 99 and 121. The orbit insertion observations were used because the whole disc of Venus was captured in the field of view, as the initial orbit of Venus Express in April 2006 was extremely large. The distance from Venus at the time of these two observations was approximately $214,000 \mathrm{~km}$ and $315,000 \mathrm{~km}$, respectively. Nominal orbit observations were MTP03-99-2, taken on 28 July 2006 from a distance of 61,000 km, and MTP04121-0 taken on 12 April 2006 at a distance of $65,000 \mathrm{~km}$.

[11] The raw observations were spectrally and spatially binned to increase the signal-to-noise ratio of the data, as well as to reduce the number of spectra needed to achieve complete spatial coverage over the observation image. As the spatial scale of each observation varied, a bin of various widths was used for different observations. A typical bin width of $20 \times 20$ pixels would be used, which is then shifted 
Table 1. Summary of the Observations Used in This Analysis and Their Important Parameters ${ }^{\mathrm{a}}$

\begin{tabular}{lccccc}
\hline $\begin{array}{c}\text { Observation } \\
\text { Name }\end{array}$ & $\begin{array}{c}\text { Integration } \\
\text { Time }(\mathrm{s})\end{array}$ & $\begin{array}{c}\text { Number } \\
\text { of Spectra }\end{array}$ & $\begin{array}{c}\text { Longitude } \\
\text { Ranges }\left({ }^{\circ}\right)\end{array}$ & $\begin{array}{c}\text { Latitude } \\
\text { Ranges }\left({ }^{\circ}\right)\end{array}$ & $\begin{array}{c}\text { Subsolar } \\
\text { Longitude }\left({ }^{\circ}\right)\end{array}$ \\
\hline CIOB00-0 & 8.0 & 300 & $0.0: 359.9$ & $-0.77:-90$ & 70.74 \\
CIOB03-7 & 8.0 & 375 & $0.0: 359.9$ & $13.16:-89.65$ & 83.69 \\
MTP03-99-2 & 8.0 & 300 & $196.71: 286.17$ & $-22.6:-76.07$ & 39.71 \\
MTP04-121-0 & 3.3 & 289 & $0.00: 360.0$ & $-13.13:-82.69$ & 107.69 \\
\hline
\end{tabular}

${ }^{\mathrm{a}}$ To compare the local time aspect of each observation, subtracting the longitudes by the subsolar longitude will yield the local time in units of longitude.

by 10 pixels across the image for adequate Nyquist sampling. An average of some 300 spectra per observation would be generated in this manner. The associated latitudes, longitudes, and geometries is also averaged in this way. The result can be seen in an example (Figure 1) from observation CIOB00.

\section{Radiative Transfer Modeling}

\subsection{Spectral Data}

[12] We employ a radiative transfer model to generate synthetic spectra, initially developed for the analysis of Galileo/NIMS data [Irwin et al., 2004], which uses the method of correlated- $k$ [Lacis and Oinas, 1991] to calculate the absorption coefficients of the gases in the atmosphere. The $k$ tables are precalculated from line-by-line spectral databases. The tables are calculated on a grid of 20 evenly spaced log-pressure levels ( $\mathrm{e}^{-17}$ to $\mathrm{e}^{5}$ bars) and 20 evenly spaced temperature levels $(150 \mathrm{~K}$ to $760 \mathrm{~K})$. These values correspond to approximately the $120 \mathrm{~km}$ and surface height range. The spectral resolutions are calculated at $10 \mathrm{~nm}$ and $1 \mathrm{~nm}$ which correspond to the resolutions of the VIRTIS-M and $\mathrm{H}$ subsystems. For gaseous opacity, the HITEMP database is used for $\mathrm{CO}_{2}$, while the remaining trace gases use HITRAN2K. A $\mathrm{CO}_{2}$ sub-Lorenztian lineshape from Tonkov et al. [1996] was implemented, with a cutoff of $150 \mathrm{~cm}^{-1}$ from the line center. $\mathrm{CO}_{2}-\mathrm{CO}_{2}$ self-broadening

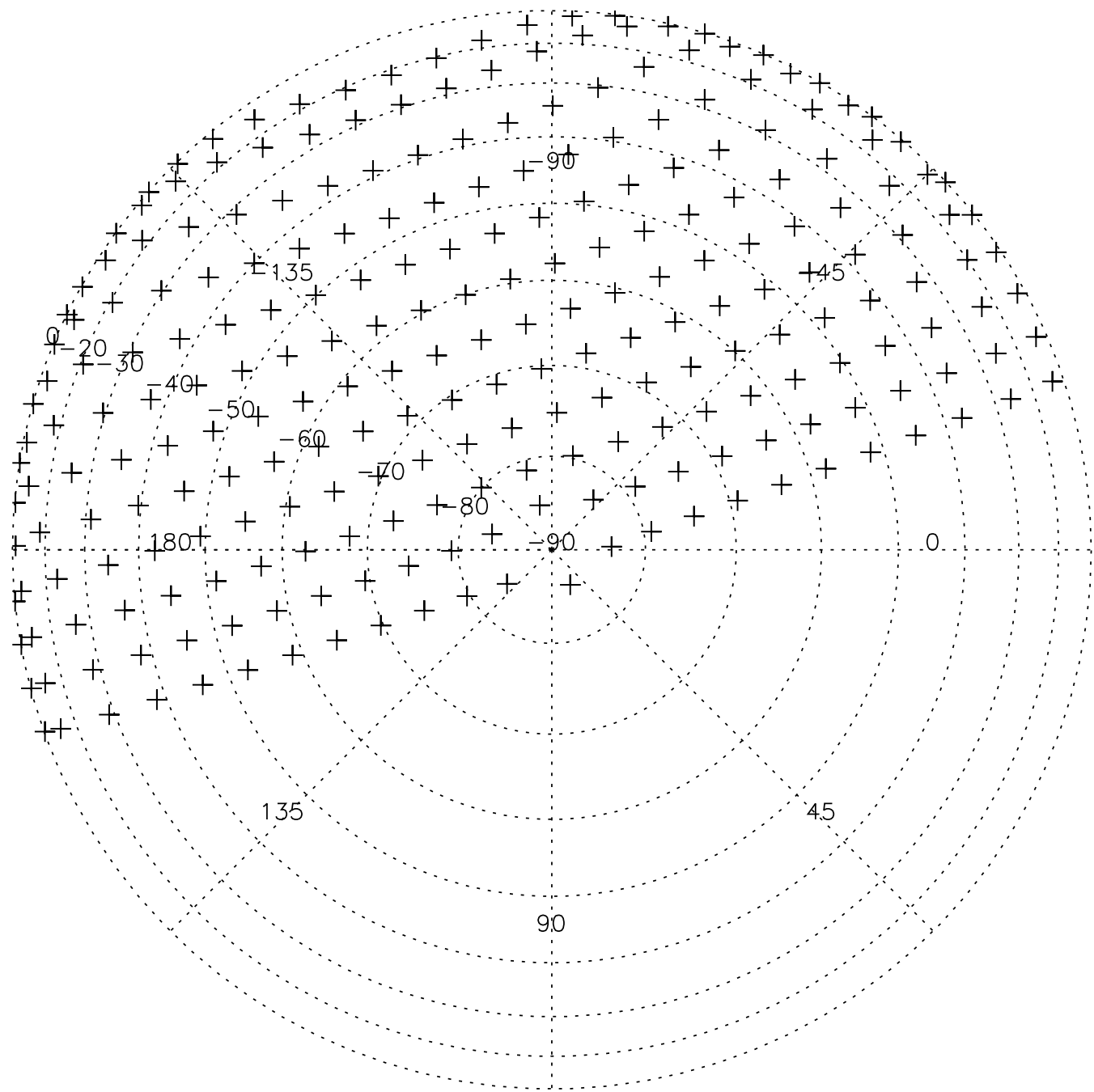

Figure 1. A typical binning scheme used to reduce the data to manageable sizes, as well as increasing the signal-to-noise ratio. This example is taken from orbit insertion observation CIOB00. Only nightside data can be used for this analysis, hence we only use data from half of the hemisphere. 


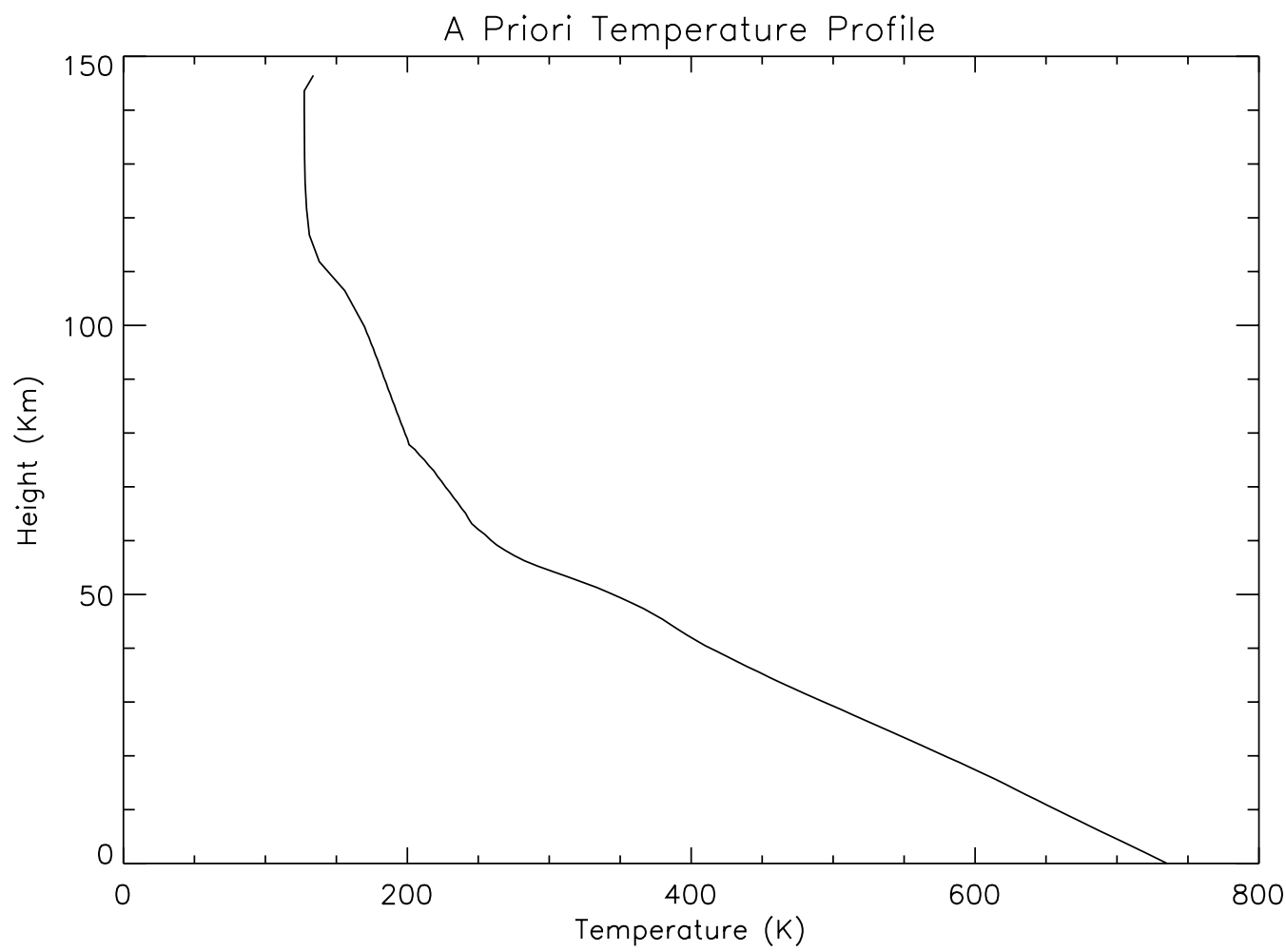

Figure 2. The Venus a priori temperature profile used in the retrieval processes taken from Seiff [1983].

half-widths were taken from the HITEMP database, while the $\mathrm{CO}_{2}-\mathrm{H}_{2} \mathrm{O}$ foreign half-widths were taken from Delaye et al. [1989]. The other remaining gases use the air-broadened half-widths given in HITRAN2K. $\mathrm{CO}_{2}$ collision induced absorption is parameterized according to Bezard et al. [1990], with a value of $3.5 \times 10^{-8} \mathrm{~cm}^{-1}$ amagat $^{-2}$ used as the opacity factor.

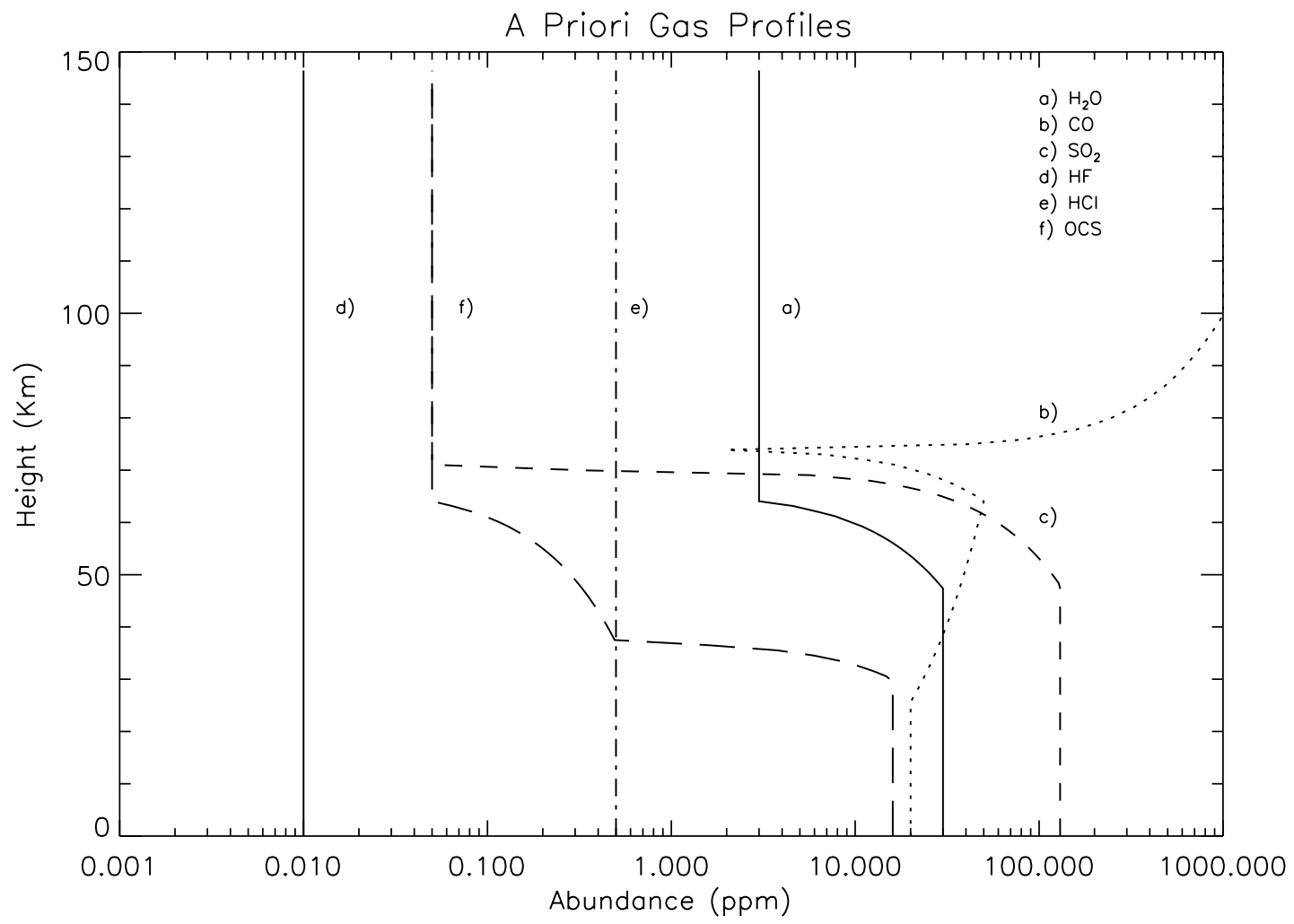

Figure 3. A priori concentrations of minor constituents as a function of height. 


\subsection{Atmospheric Profiles}

[13] The temperature profile used as the a priori was taken from Seiff [1983] and is plotted in Figure 2. The a priori vertical distribution of gases is given in Figure 3. The amount of $\mathrm{CO}_{2}$ is 0.965 fractional abundance, which is assumed to be vertically uniform. The abundance of $\mathrm{CO}$ and HF has been taken from Collard [1993], where HF is uniform, and kept uniform during the retrieval process, at $0.005 \mathrm{ppm}$. The remaining vertical profiles have been taken from Marcq et al. [2005], who have taken their profiles from a mixture of Oyama et al. [1980], Von Zahn et al. [1983], and Taylor et al. [1997].

\subsection{Cloud Profile}

[14] We use an a priori cloud model which follows the vertical profiles of Pollack et al. [1993]. The clouds in the model extend from $50 \mathrm{~km}$ to some $80 \mathrm{~km}$. There are four modes in the model, which are distinguished by their size parameter. The refractive indices used in the model have been taken from Palmer and Williams [1975], for a mixture of $75 \%$ sulphuric acid and $25 \%$ water vapor. This is in line with other models of the near-infrared windows such as Pollack et al. [1993] and Marcq et al. [2006]. These refractive indices are used to calculate the single scattering albedo and absorption cross sections as look-up tables assuming Mie theory. Limited tests have been conducted for different mixtures of sulphuric acid/water vapor and their impact on the $2.3 \mu \mathrm{m}$ spectrum. Tests show, for concentrations of $75 \%, 85 \%$, and $96 \% \mathrm{H}_{2} \mathrm{SO}_{4}$, the change to the ratio value at $2.30 / 2.33 \mu \mathrm{m}$ (radiance outside the $\mathrm{CO}$ absorption band to radiance inside the band) is on the order of much less than $1 \%$. This shows that we are really not that sensitive to potential changes in concentrations of $\mathrm{H}_{2} \mathrm{SO}_{4} /$ $\mathrm{H}_{2} \mathrm{O}$ in the Venus atmosphere.

[15] To account for the multiple-scattering atmosphere and aerosols, as well as to accurately model high emissionangle observations, we use a matrix operator method to calculate for multiple scattering of the radiation [Plass et al., 1973]. We calculate this using ten streams (five up, five down).

\section{Analysis}

[16] The retrieval model used in this work, named Nonlinear Optimal Estimator for Multivariate Spectral Analysis (NEMESIS), follows the formulation of Rodgers [1976]. The retrieval scheme starts with the prescribed forward model synthetic spectrum, generated with an a priori atmosphere, described above. The convergence limit $\phi$ (denoted $\left.\phi_{\text {limit }}\right)$ is also required by the user to start the iterative process. This produces a predicted spectrum $\mathbf{y}_{\mathbf{n}}$ with an initial cost function $\phi_{i}$, given by

$$
\phi=\left(\mathbf{y}_{\mathbf{m}}-\mathbf{y}_{\mathbf{n}}\right)^{\mathrm{T}} \mathbf{S}_{\mathbf{m}}^{-1}\left(\mathbf{y}_{\mathbf{m}}-\mathbf{y}_{\mathbf{n}}\right)+\left(\mathbf{x}-\mathbf{x}_{\mathbf{a}}\right)^{T} \mathbf{S}_{\mathbf{x}}^{-1}\left(\mathbf{x}-\mathbf{x}_{\mathbf{a}}\right)
$$

where $\mathbf{y}_{\mathrm{m}}$ is the measured radiance, $\mathbf{y}_{\mathrm{n}}$ is the predicted radiance, $\mathbf{S}_{\mathrm{m}}$ is the measurement covariance matrix, $\mathbf{x}$ is the state vector, $\mathbf{S}_{\mathbf{x}}$ is the state vector covariance matrix, and $\mathbf{x}_{\mathbf{a}}$ is the a priori state vector. The measurement covariance matrix $\mathbf{S}_{\mathbf{m}}$ contains both the measurement errors and the forward modeling errors. The forward modeling error is included to compensate for any lack of physics within the forward model, as well as any inaccuracies incurred when using the correlated- $k$ approximation. The calculation and estimates of the forward modeling and a priori errors can be found in the work of Irwin et al. [2008a] and Tsang et al. [2008], respectively, and are negligible overall.

[17] The first term on the right-hand side of the cost function is known as $\chi^{2}$ and is a measure of how well the synthetic spectrum is fitting to the observed spectrum. It is $\phi$ which is minimized to arrive at a possible solution. Ultimately, the optimized solution to the nonlinear problem can be found for the unknown state vector by solving

$$
\mathbf{x}_{i+1}=\mathbf{x}_{\mathbf{a}}+\mathbf{S}_{\mathbf{x}} \mathbf{K}_{i}^{T}\left(\mathbf{K}_{i} \mathbf{S}_{\mathbf{x}} \mathbf{K}_{i}^{T}+\mathbf{S}_{\mathbf{m}}\right)^{-1}\left(\mathbf{y}_{\mathbf{m}}-\mathbf{y}_{i}-\mathbf{K}_{i}\left(\mathbf{x}_{\mathbf{a}}-\mathbf{x}_{i}\right)\right)
$$

where $\mathbf{K}_{\mathbf{i}}$ is the $\mathbf{K}$ matrix associated with the $i$ th iteration state vector $\mathbf{x}_{\mathrm{i}}$. A modification is added to this GaussNewton iteration with the addition of a "braking parameter," $\lambda$, to keep the iteration stable for cases where the problem is nonlinear and is given by a LevenbergMarquardt constraint of the form

$$
\mathbf{x}_{i+1}^{\prime}=\mathbf{x}_{i}+\frac{\left(\mathbf{x}_{i+1}-\mathbf{x}_{i}\right)}{1+\lambda}
$$

where $\mathbf{x}_{i+1}^{\prime}$ is the modified state vector. If $\mathbf{x}_{i+1}^{\prime}$ makes the fit worse, $\lambda$ is increased and $\mathbf{x}_{i+1}^{\prime}$ is calculated again. If $\mathbf{x}_{i+1}^{\prime}$ 239 yields a better fit, $\lambda$ is decreased and the iteration continues.

[18] The iterative process then proceeds to take a predefined a priori covariance error $\mathbf{S}_{\mathbf{a}}$, the measured spectrum $\mathbf{y}_{\mathbf{m}}$, and the accompanied measurement covariance (error) $\mathbf{S}_{\mathbf{m}}$. This produces an estimate of the state vector $\mathbf{x}$, with which a new spectrum $\mathbf{y}_{\boldsymbol{n}}$ is calculated using the radiative transfer equations. This $\mathbf{y}_{\boldsymbol{n}}$ has an accompanied $\phi_{n}$. If this $\phi_{n}$ is greater than the previous $\phi_{(n-1)}$, the braking parameter (equation (3)) is increased by tenfold and the iteration begins again. If $\phi_{n}$ is less than the previous $\phi$ value, braking parameter $\lambda$ is decreased to $0.3 \lambda$ and the next iteration begins. This iteration scheme terminates when

$$
\frac{\phi_{n-1}-\phi_{n}}{\phi_{n}}<\phi_{\lim i t}
$$

where $\phi_{\text {limit }}$ is a percentage change. This yields a possible state of the atmosphere $\mathbf{x}_{\boldsymbol{i}}$, given the initial measured spectrum $\mathbf{y}_{\mathbf{m}}$. In this work, the retrieval model terminates when the number of runs reaches a maximum of 60 iterations, or if the change in cost function $\phi$ between iterations drops below $0.1 \%$, whichever is reached first (these values in practice change depending on the level of fit specified and time allotted). In practice, a solution is reached usually after approximately 10-20 iterations, when the cost function drops below the allotted $0.1 \%$ minimum. A full review of the radiative transfer and retrieval model used in this work can be found in the work of Irwin et al. [2008a]. 

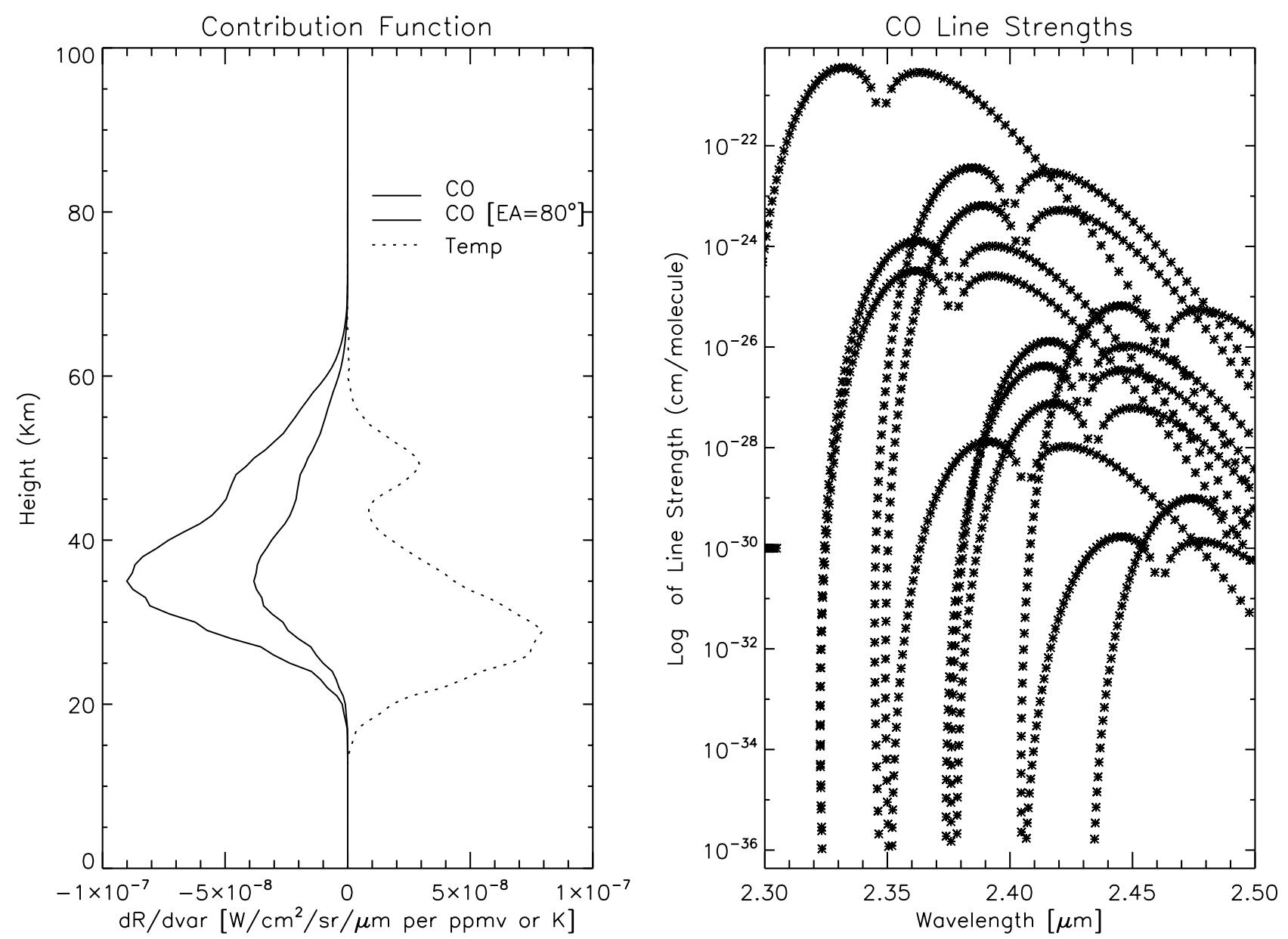

Figure 4. (left) The contribution functions at $2.35 \mu \mathrm{m}$ for the background temperature, $\mathrm{CO}$ at nadir, and $\mathrm{CO}$ at an emission angle of $80^{\circ}$. (right) The absorbing line strengths of $\mathrm{CO}$ in this spectral region.

[19] Figure 4, left, shows the nadir contribution functions for $2.35 \mu \mathrm{m}$, produced by the radiative transfer model, which shows the background emissions coming from $30 \mathrm{~km}$, with a sensitivity to $\mathrm{CO}$ at $35 \mathrm{~km}$. Between 2.30 and $2.5 \mu \mathrm{m}$, the rotational-vibrational lines of the $2-0$ band of carbon monoxide are active [Bezard et al., 1990], the spectral lines of which are also shown in Figure 4, right. It is these lines which provide us with the ability to retrieve the concentration of $\mathrm{CO}$ in the $35 \mathrm{~km}$ height range.

[20] We take the entire spectral range, from 2.20 to $2.50 \mu \mathrm{m}$, to retrieve the tropospheric carbon monoxide concentrations. A sample spectrum can be seen in Figure 5. From wavelengths of 2.18 to $2.30 \mu \mathrm{m}$, the absorption is dominated by the presence of $\mathrm{CO}_{2}$. The radiation is also attenuated by the intervening cloud layer. This attenuation has a predominantly gray effect over this entire spectral window [Bezard et al., 1990; Marcq et al., 2006; Pollack et al., 1993]. Thus, the spectra covering these wavelengths are used to fit to the varying optical depths of the clouds across the planet. Once this is done, the rest of the spectra, from 2.30 to $2.50 \mu \mathrm{m}$, are assumed to have the same absorption as that caused by the clouds from 2.18 to $2.30 \mu \mathrm{m}$.

[21] The remaining absorption in this region is due to the presence of trace gases which are active absorbers in this spectral region. The sensitivity of this spectrum in wavelength and height of trace gases can be found in the work of
Tsang et al. [2008] and Baines et al. [2006]. While we fit the 2-0 band of $\mathrm{CO}$ from 2.30 to $2.35 \mu \mathrm{m}$, we also simultaneously fit the rest of the spectrum to retrieve abundances for $\mathrm{H}_{2} \mathrm{O}$ and OCS, the results of which will not be shown in this work as it has no impact on the retrieved $\mathrm{CO}$ abundances. An example of our ability to fit our synthetic spectra to the data is shown in Figure 5. The residual, a simple difference between the measured and the synthetic spectrum, is also shown in Figure 5. Once $\phi$ has been minimized, a best estimate for the $\mathrm{CO}$ abundance is found. In the case of $\mathrm{CO}$, we retrieve a scaling factor which is multiplied by the a priori profile to yield a new abundance. Since the peak of the contribution function for $\mathrm{CO}$ is at approximately $35 \mathrm{~km}$, we will show the abundances for that altitude.

\section{Results}

[22] Figure 6 shows the observation and the results from the first orbit insertion observation, CIOB00. The $2.3 \mu \mathrm{m}$ radiances resulting from the variations in the optical depths of the clouds that are attenuating the thermal radiation from above $35 \mathrm{~km}$ are shown at the spatial resolution of the binned spectra. After spectral fitting using the method described above, we can also display the $\chi^{2} / \mathrm{n}$ values for different areas of the map, showing our ability to fit spectra 

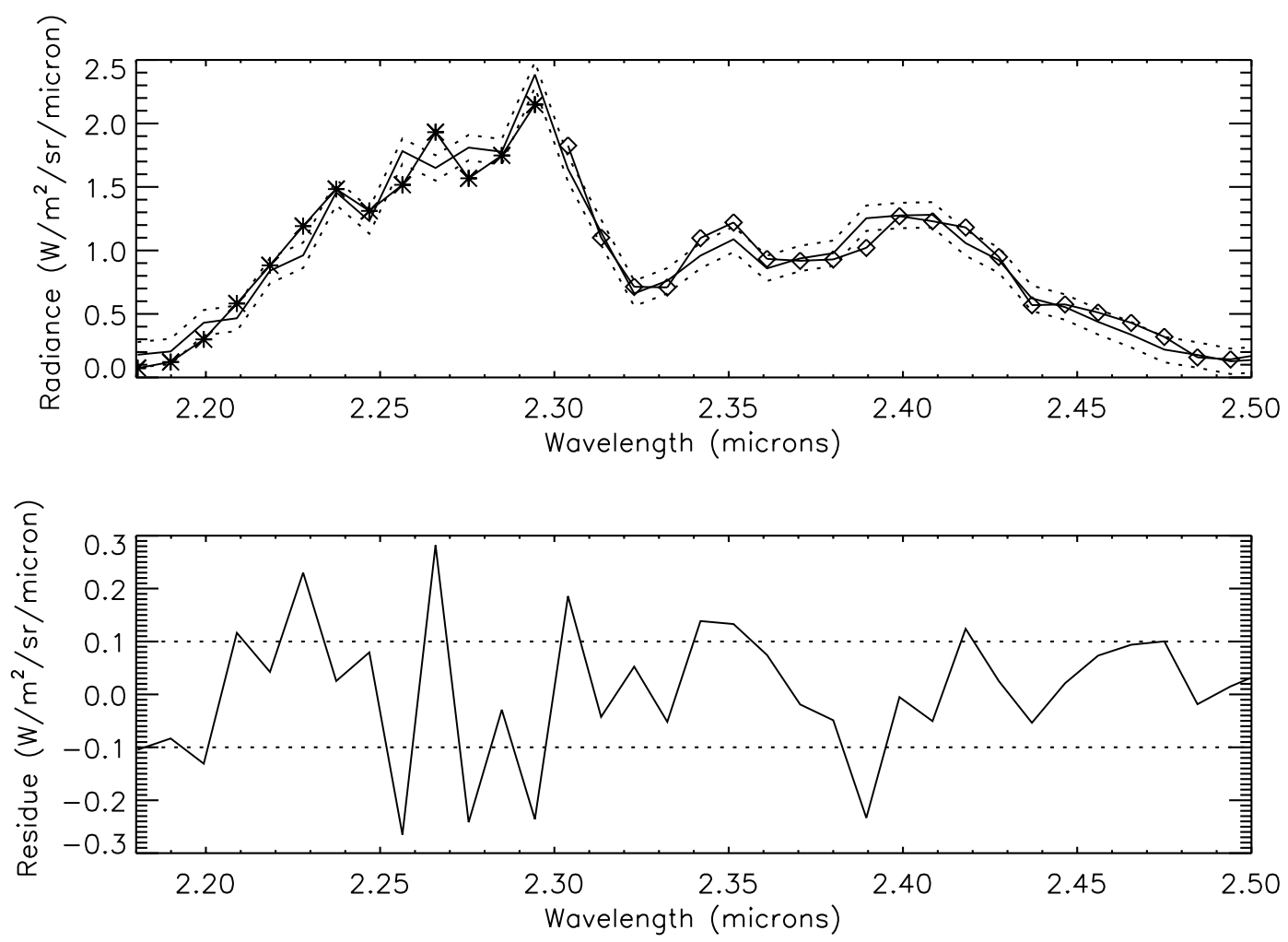

Figure 5. An example Visible and Infrared Thermal Imaging Spectrometer (VIRTIS)-M spectrum between 2.18 and $2.50 \mu \mathrm{m}$ used in this analysis. (top) Solid line (no symbol) is the measured spectrum, with dotted lines showing the limits of uncertainty in the radiances which arise from forward modeling and the measurement of the radiances. Solid, star symbol line is the model fit when fitting to cloud opacity. Solid, diamond symbol line is the model fit when fitting to $\mathrm{CO}, \mathrm{H}_{2} \mathrm{O}$, and OCS, assuming a cloud opacity derived from the solid star line. (bottom) The radiance residual between the measured and fitted spectrum.

at those precise locations. The $\chi^{2} / \mathrm{n}$ map is quite homogeneous, with values of between 1 and 3. Much higher $\chi^{2} / \mathrm{n}$ values appear near the day-night terminators and at the poles because of bad spectra and poor signal-to-noise. It should be noted here that the $\chi^{2} / n$ fitting is still in an acceptable range, even though the optical depth has increased because of the presence of the polar cloud and vortex. The primary driver of the retrieved errors is the cloud opacity. If the cloud opacity is extremely high, like at the polar vortex, the signal-to-noise reduces dramatically, and thus the retrieved errors increase as well.

[23] The resulting $\mathrm{CO}$ abundances and related errors are plotted on Figure 6. The mean retrieved errors in the abundances are of the order of 2 to $3 \mathrm{ppm}$ (approximately $10 \%$ of the retrieved variance to mean ratio abundances) in the midlatitudes. The errors then increase toward the poles and the equator. The large errors at the equator are due to the geometry of the observation during this orbit insertion phase, where the subspacecraft point was above the poles. This results in radiances with high emission angles at the equator, with reduced signal-to-noise ratios. Correspondingly, the polar regions beyond $70^{\circ} \mathrm{S}$ are also subject to low signal-to-noise because of the increase in optical depths of the polar clouds.

[24] We see that the mean equatorial values of $23 \pm 3 \mathrm{ppm}$ increase toward the poles, reaching a maximum near $60^{\circ} \mathrm{S}$, of $32 \pm 3 \mathrm{ppm}$. The distribution of $\mathrm{CO}$ poleward of $60^{\circ} \mathrm{S}$ also indicates a possible decrease in abundance. This general first-order trend of increasing from equator, reaching maximum near $/$ at $60^{\circ} \mathrm{S}$, and inversion toward the poles is best seen in Figure 6. This map also shows a degree of variability of $\mathrm{CO}$ in solar longitude. We can best see this in Figure 7, where we plot the retrieved $\mathrm{CO}$ abundances as a function of the solar longitude. Solar longitude of $-100^{\circ}$ corresponds to the dusk terminator, while $-260^{\circ}$ corresponds to the dawn terminator. The first-order trends are apparent, but variability seen in Figure 7 as a function of solar longitude indicates a number of general features which are of note: (1) The mean abundance of $\mathrm{CO}$ on longitudes near the dusk terminator has greater absolute value than post local midnight and near dawn. (2) The maximum of the $\mathrm{CO}$ abundance near dusk is at $60^{\circ} \mathrm{S}$, while the $\mathrm{CO}$ maximum near dawn is closer to $70^{\circ} \mathrm{S}$. (3) Midlatitude (approximately $40^{\circ} \mathrm{S}$ ) abundances of $\mathrm{CO}$ at approximately $26 \pm 2 \mathrm{ppm}$ have less variation than at other latitudes.

[25] The same picture is painted with observation CIOB03, taken some $96 \mathrm{~h}$ later, again from orbit insertion (Figure 8). The same evening/morning asymmetry in the $\mathrm{CO}$ abundance can be seen, although it is less pronounced in this observation than CIOB00. Less of the equator is seen as CIOB03 was taken in the ascending branch of the Venus Express orbit. We also note that the midlatitude values are very constant across solar longitude, while variability can be seen in the dusk and dawn part of the nightside disc. It 

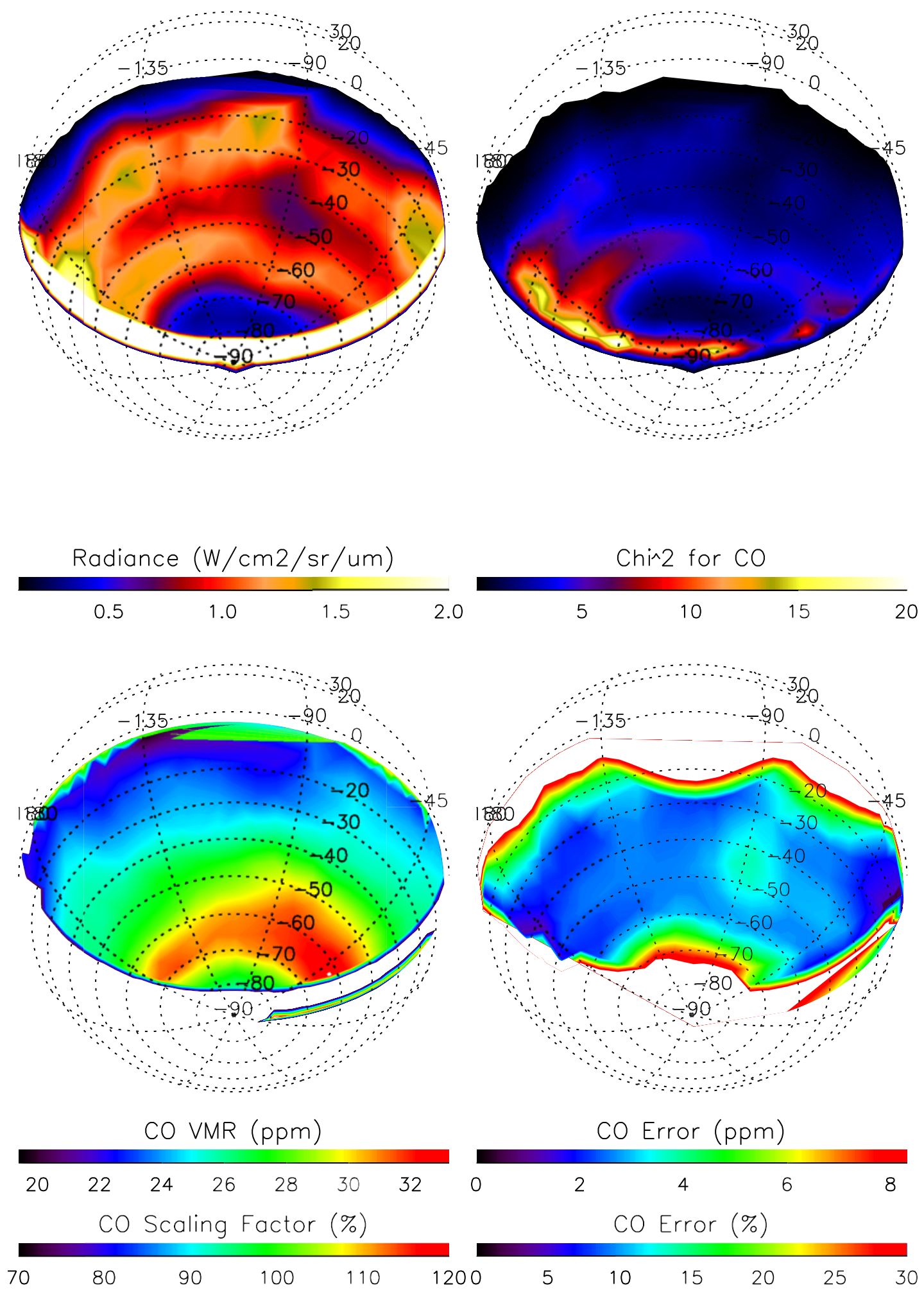

Figure 6. Orbit Insertion Observation CIOB00: (top left) $2.301 \mathrm{~m}$ radiance, a proxy for cloud opacity, plotted after binning; (top right) $\chi^{2} / \mathrm{n}$ values when fitting for $\mathrm{CO}$ between 2.30 and $2.35 \mu \mathrm{m}$; (bottom left) the retrieved $\mathrm{CO}$ abundance at $35 \mathrm{~km}$; and (bottom right) the error in the retrieved $\mathrm{CO}$ abundance. Areas of the observation where the retrieved error exceeds $8 \mathrm{ppm}$ are colored white. Regions of high $\chi^{2} / \mathrm{n}$ are reflected in the map of the retrieved errors (in white). 


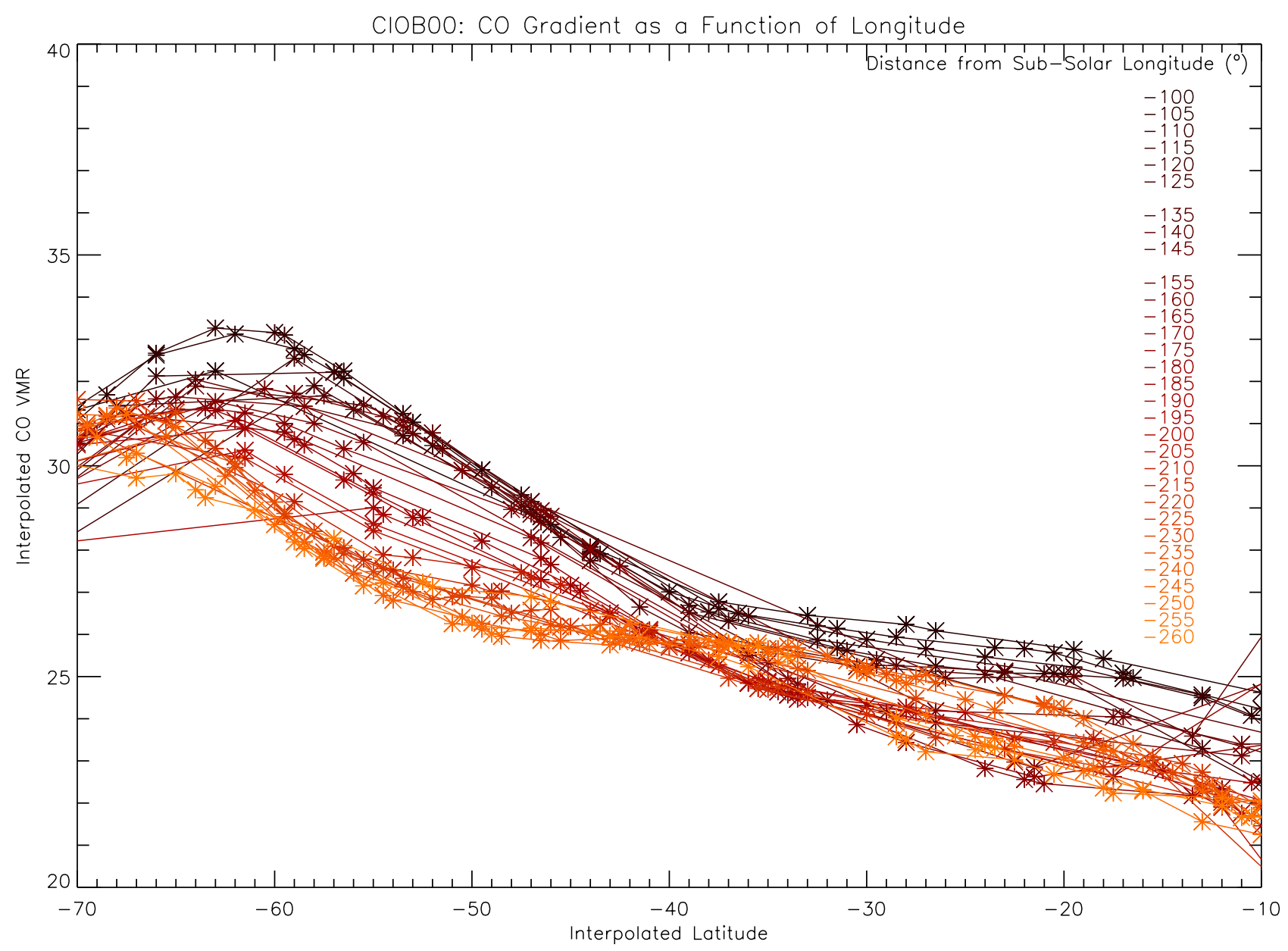

Figure 7. The retrieved $\mathrm{CO}$ gradient versus latitude from $\mathrm{CIOB} 00$ observation, plotted as a function of solar longitude, interpolated in spacings of $5^{\circ}$. These retrieved $\mathrm{CO}$ abundances are referenced to $35 \mathrm{~km}$. Dusk terminator at $-100^{\circ}$ and dawn terminator at $-260^{\circ}$.

should also be noted that the mean abundances at $60^{\circ} \mathrm{S}$ for CIOB00 and CIOB03 are 32 and $34 \pm 2$ ppm, respectively.

[26] To investigate some of these features further, to enhance the sampling and to see the if the degree of variability of $\mathrm{CO}$ concentrations changes over time, we take observations from the nominal orbit during "case 2 " observations, MTP03-99-2 and MTP04-121-0. These are shown in Figures 9 and 10, respectively. MTP03-99-2 shows a constant band of maximum CO abundance of between 35 to $36 \pm$ $2 \mathrm{ppm}$ at a latitude of $60^{\circ} \mathrm{S}$. Zonal variability at this latitude can just be made out, with local maxima of $\mathrm{CO}$ at -90 and $-135^{\circ} \mathrm{W}$ and a minimum at approximately $-112^{\circ} \mathrm{W}$, with a value of $34 \mathrm{ppm}$. However, it should be noted that the retrieved error is of the order of these fluctuations and therefore is not entirely without doubt. In addition, the maximum in $\mathrm{CO}$ commencing at $60^{\circ} \mathrm{S}$ continues at a steady value until as high as $70^{\circ}$, where a slight decrease in the abundance past $70^{\circ} \mathrm{S}$ can be made out. The retrieved errors in this region have not increased significantly. Observation MTP04-121-0 shows a similar trend. Again, the CO maximum is located at $60^{\circ} \mathrm{S}$, with mean upper limit of $36 \pm$ $3 \mathrm{ppm}$, but in this instance seems more localized around a longitude of $-45^{\circ} \mathrm{W}$, decreasing by $3 \mathrm{ppm}$ toward $-68^{\circ} \mathrm{W}$. However, caution should be taken again as this decrease is of the order of the retrieved error. The decrease from $65^{\circ} \mathrm{S}$ in the $\mathrm{CO}$ abundance to $30 \mathrm{ppm}$ toward the poles is matched by increased error caused by the increase in the cloud optical depth of the polar vortex, decreasing the signal-tonoise ratio. Therefore, we cannot fully confirm the validity of the overturning from this image alone.

\section{Discussion}

[27] We first confirm the equator-to-pole increase of $\mathrm{CO}$ in the troposphere first seen by Collard et al. [1993] from Galileo/NIMS data, validated by Marcq et al. [2006] from IRTF/SpeX data. It is also consistent with observations made by Marcq et al. [2008], using much higher spectral resolution subsystem of VIRTIS-H, who have shown very similar results for both equatorial and polar values of $\mathrm{CO}$. The authors of the above work found a $30 \pm 15 \%$ in- crease from $0^{\circ}$ to $60^{\circ}$, corresponding to $24 \pm 3$ to $31 \pm 2 \mathrm{ppm}$ at $36 \mathrm{~km}$. This is very consistent with the results of this paper, which show on first order, an increase in the same latitude range of $23 \pm 2$ to $32 \pm 2 \mathrm{ppm}$ at the same altitude.

[28] In addition, because of the unique imaging capabilities of the VIRTIS-M subsystem, this analysis has also possibly revealed two new features in the tropospheric $\mathrm{CO}$ 

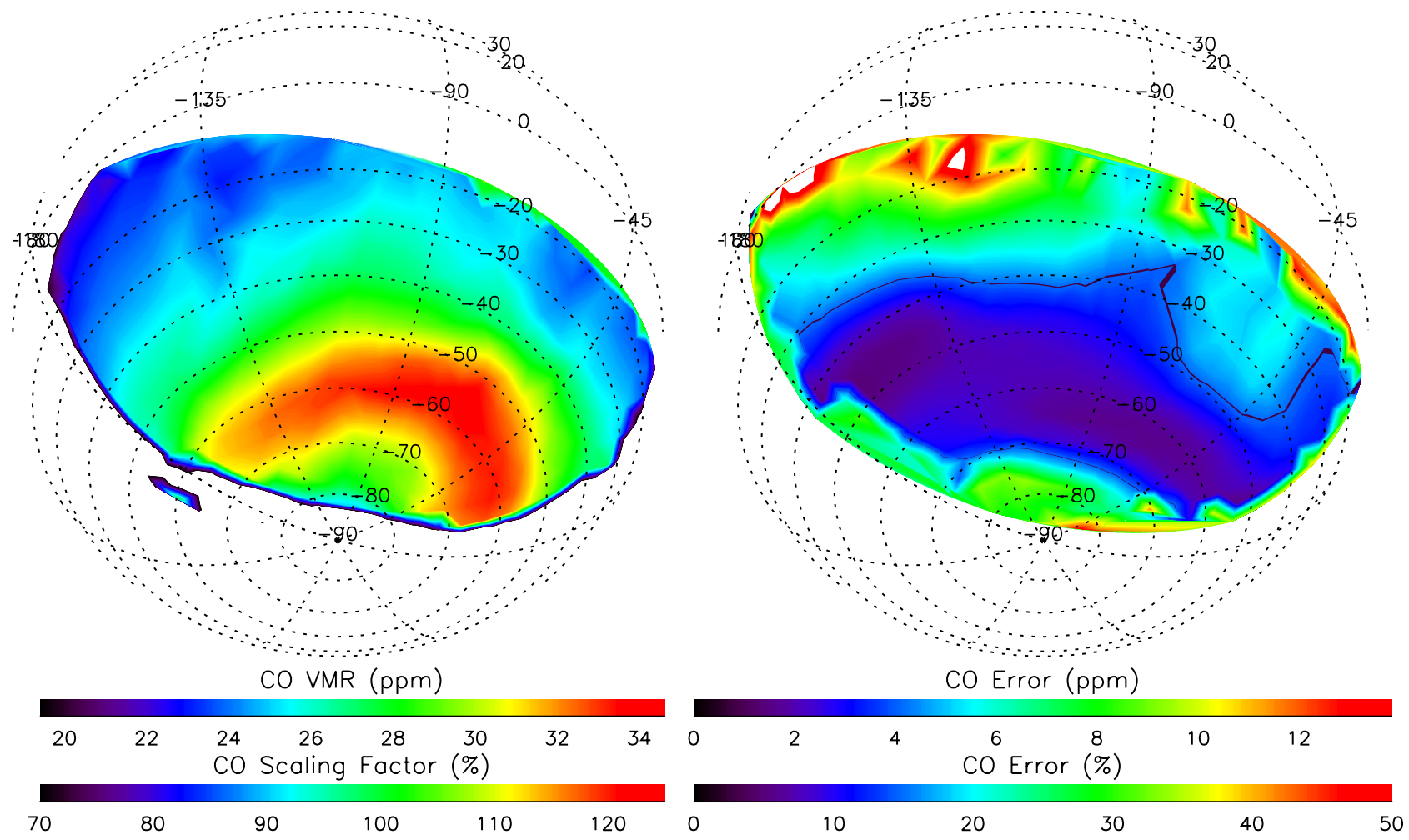

Figure 8. Orbit Insertion Observation CIOB03: (left) Retrieved CO abundance at $35 \mathrm{~km}$ with (right) the associated retrieval errors. Areas of the observation where the retrieved error exceeds 8 ppm are colored white.

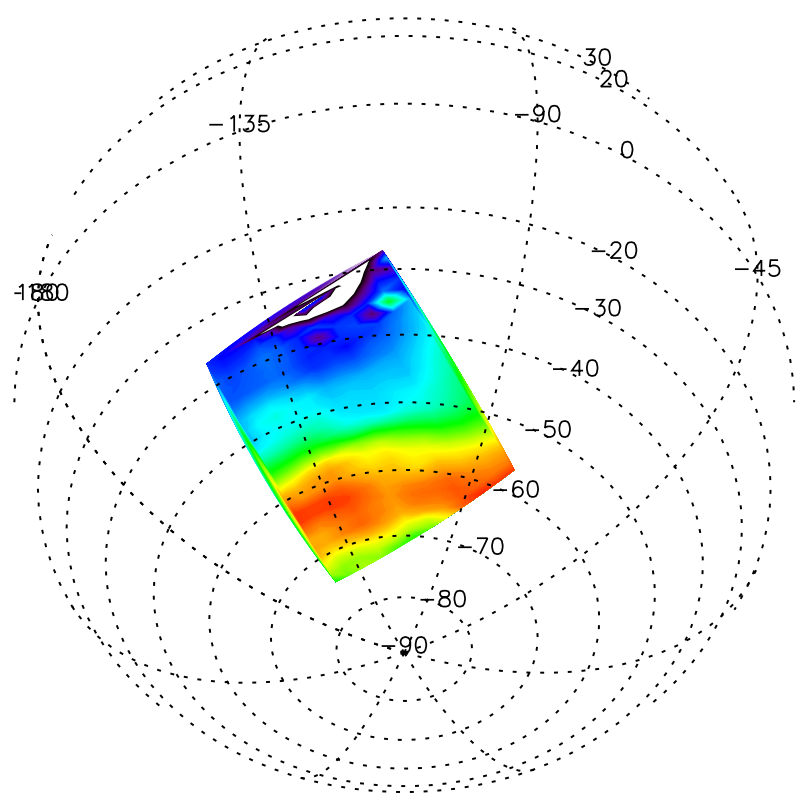

CO VMR (ppm)

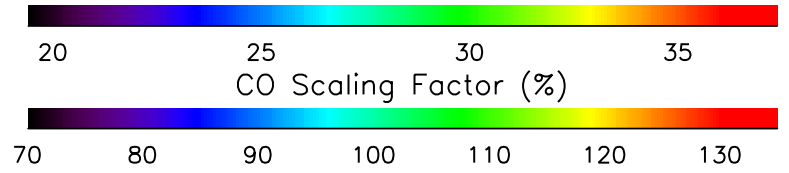

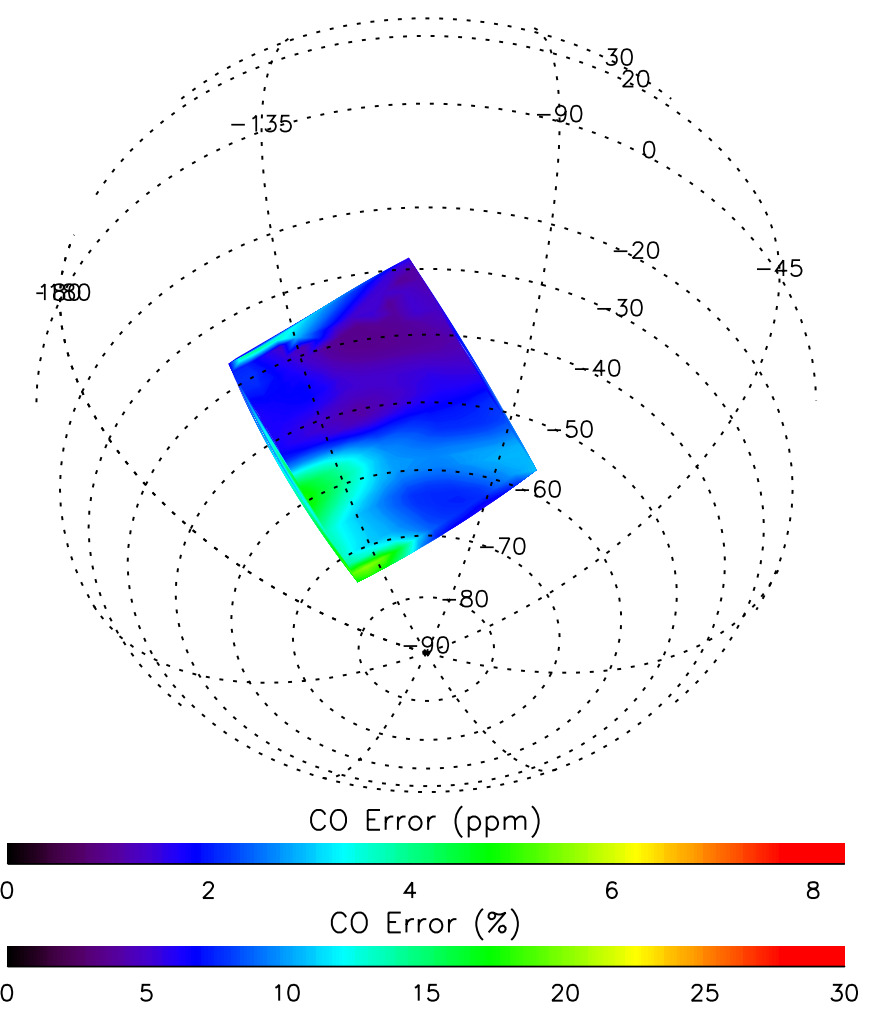

Figure 9. (left) The retrieved $\mathrm{CO}$ abundance at $35 \mathrm{~km}$ and (right) the errors for observation MTP03-99-2. Variability in the $\mathrm{CO}$ abundance at $60^{\circ} \mathrm{S}$ across different longitudes can be seen. 

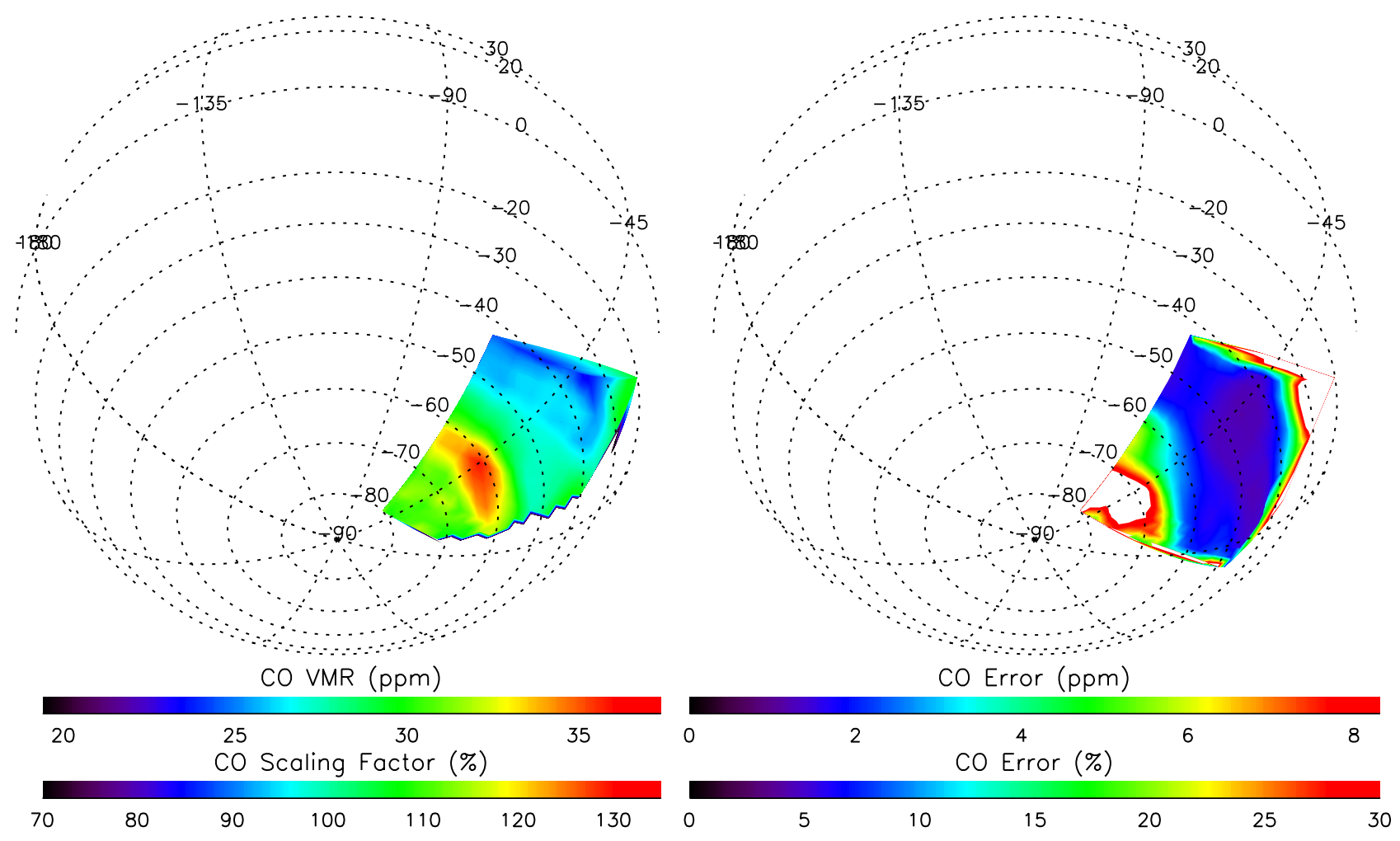

Figure 10. (left) Retrieved CO from observation MTP04-121-0, with (right) the retrieved errors. Areas of the observation where the retrieved error exceeds $8 \mathrm{ppm}$ are colored white.

distribution which have not been previously observed and warrant further discussion: the evening/morning asymmetry in the $\mathrm{CO}$ zonal profiles and the reversal in $\mathrm{CO}$ concentration poleward of $60^{\circ}$. Both these features can be explained by a combination of the Hadley-type circulation, as depicted in Figure 11, and photochemistry from the cloud tops.
[29] In regard to the overturning of $\mathrm{CO}$ past $60^{\circ} \mathrm{S}$, the mechanism for this is likely to be purely dynamical in nature. The general idea is that the descending branch of the Hadley cell occurs at $60^{\circ}$. This is consistent with GCM models such as Lee et al. [2007] where the maximum downwelling occurs at $60^{\circ} \mathrm{N} / \mathrm{S}$. It is also consistent with measurements of the dayside meridional winds from Pioneer

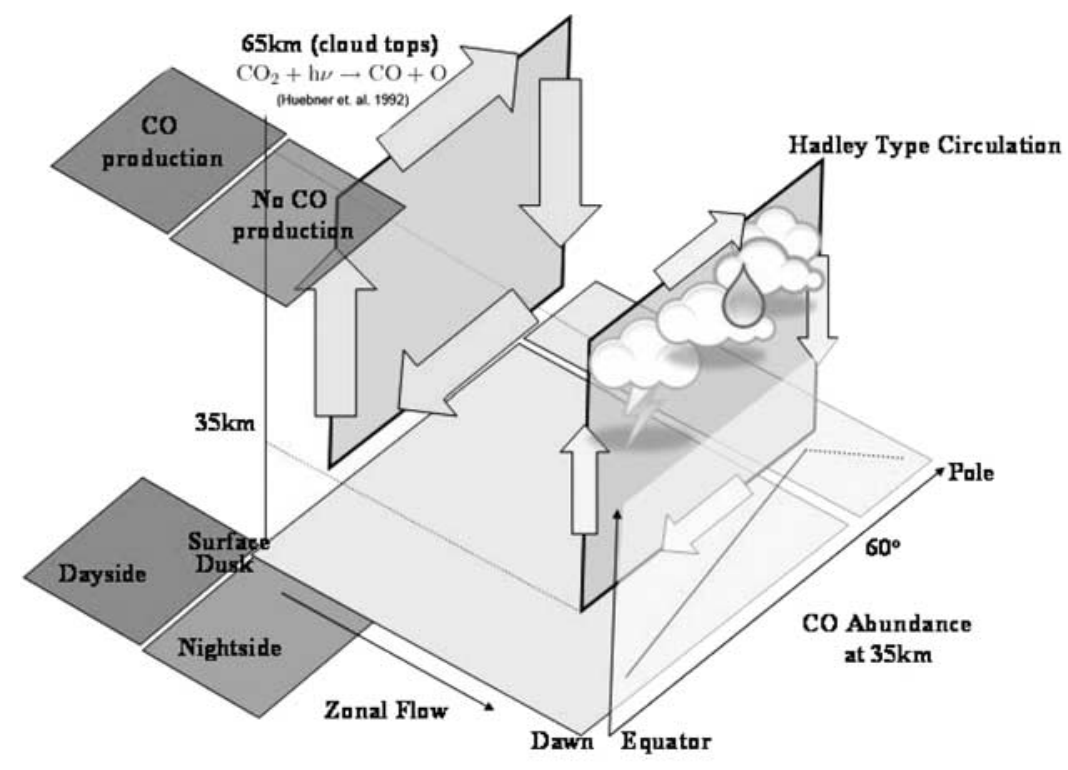

Figure 11. A pictorial representation of the Hadley cell type circulation which exists in the Venus atmosphere. A complex interplay between dynamical and chemical cycles combines to yield the features seen in the retrieved CO maps. Photo-disassociation reaction taken from Huebner et al. [1992]. 
Venus which indicate the horizontal convergence of the meridional flow is greatest between 50 and $60^{\circ}$ [Limaye, 2007]. We expect the maximum downwelling of the Hadley cell to be associated with regions of maximum vertical winds, and therefore would bring the most $\mathrm{CO}$ rich air from mesosphere $(>65 \mathrm{~km})$ to the troposphere. If this downwelling is greatest at $60^{\circ}$, it implies a poleward decrease in $\mathrm{CO}$ concentration past $60^{\circ} \mathrm{S}$, and therefore would be consistent with our observations.

[30] The situation with respect to the east-west asymmetry in the $\mathrm{CO}$ abundances is probably a mixture of photochemistry and dynamics processes, which is responsible for the concentration of $\mathrm{CO}$ at this altitude since the dominant chemistry occurs way above or way below this $35 \mathrm{~km}$ region. The supply of $\mathrm{CO}$ is governed by the upper atmosphere source. The two options to create this east-west asymmetry in $\mathrm{CO}$ at $35 \mathrm{~km}$ is either an east-west gradient in the source of $\mathrm{CO}$ in the source region and constant downwelling, or a constant source of $\mathrm{CO}$ in the source region and an east-west gradient in the downwelling across longitudes. It is indeed likely to be a combination of both processes.

[31] The evening/morning asymmetry seen in Figures 6 and 8 can be, on first order, simply a function of the photochemistry which is occurring at the cloud tops at $65 \mathrm{~km}$. If we consider what is occurring at the cloud tops, during the early morning, we would expect a minimum in the early morning with a ramp up of CO production in the morning sunshine due to the photolysis by solar UV, and would depend on the photolysis rate of $\mathrm{CO}$ above the clouds. This would peak in the early evening (before sunset probably). Maps of $\mathrm{CO}$ on the nightside of Venus above the clouds [Irwin et al., 2008b] indicate enhanced CO at the evening terminator and are consistent with these observations of the tropospheric $\mathrm{CO}$ and photochemical mechanisms above the clouds. As the photolysis stops because of the lack of sunlight, no more $\mathrm{CO}$ is produced on the nightside. The meridional circulation, however, will continue to pump mesospheric air into the lower troposphere. At the start of the evening you would therefore expect high abundances of $\mathrm{CO}$ in the lower atmosphere at the location of the downwelling of the Hadley cell and for this concentration to decay as the night progresses, assuming the vertical velocity of this downwelling was constant across the nightside (which is most likely not the case). However, $\mathrm{CO}$ is constantly being destroyed by sink reactions, most notably by OCS [Pollack et al., 1993] and $\mathrm{S}_{2}$ [Hong and Fegley, 1997], and reconverted back to $\mathrm{CO}_{2}$. Therefore, we also need to know something about the creation and destruction rates for $\mathrm{CO}$ in the lower atmosphere, as well as the meridional overturning rates $\left(10 \mathrm{~m} \mathrm{~s}^{-1}\right.$ poleward winds at 100 mbar). From the observations of Figures 6 and 8 , a change in the concentration of $\mathrm{CO}$ of $2 \mathrm{ppm}$ from the evening to morning terminator can be seen. There may be some problem accounting for this given what is known about the reaction rates and atmospheric dynamics.

\section{Conclusions}

[32] Observations of the nightside of Venus taken from Venus Express/VIRTIS-M instrument at wavelengths between 2.20 to $2.50 \mu \mathrm{m}$ have been used to measure and map the distribution of $\mathrm{CO}$ in the troposphere of Venus. We have taken spectra from four different observations, two from orbit insertion, and two from the nominal orbit, which are then coadded and binned for increased signal-to-noise and homogeneous spatial sampling. We use a spectral fitting algorithm to first account for variations in the cloud optical depth by fitting spectra from 2.20 to $2.30 \mu \mathrm{m}$. This is then followed by fitting the remaining spectra from 2.30 to $2.35 \mu \mathrm{m}$, which is sensitive to the 2-0 CO band, by scaling a known a priori profile.

[33] We first confirm the presence of the $\mathrm{CO}$ enhancement from equator to pole, with a mean increase of between $40 \%$ and $45 \%$ from $23 \pm 2 \mathrm{ppm}$ to $32 \pm 2 \mathrm{ppm}$, which is consistent with observations made by the Galileo/NIMS flyby of Venus in 1990 . We find the peak value of CO to occur between 55 and $65^{\circ} \mathrm{S}$. We also find evidence of two possibly new features in this $\mathrm{CO}$ gradient; decreases of $\mathrm{CO}$ poleward of $60^{\circ} \mathrm{S}$ and variability in longitude.

[34] A mixture of photochemistry and dynamics will be responsible for the concentration of $\mathrm{CO}$ at this altitude because the dominant chemistry does not occur near $35 \mathrm{~km}$. Advection of $\mathrm{CO}$ from below is unlikely because of a lack of a continuous source, leaving photolysis of $\mathrm{CO}_{2}$ above $60 \mathrm{~km}$ as the most likely source of $\mathrm{CO}$ in the lower atmosphere. The $\mathrm{CO}$ is then advected into the lower atmosphere, particularly in the downwelling region near $60^{\circ}$, where it is destroyed. Given the need for sunlight to photolyse the $\mathrm{CO}_{2}$, the distribution of $\mathrm{CO}$ at the source altitude probably follows the solar zenith angle, peaking in the afternoon hemisphere because of the background flow. Poleward advection in the source region and downwelling at the poles then transports the $\mathrm{CO}$ into the lower atmosphere, producing the observed latitudinal gradient at $35 \mathrm{~km}$. These observations would then place the downwelling branch of the Hadley cell near $60^{\circ}$, consistent with observations of peak westward flow at $60^{\circ}$ and GCM simulations such as Lee et al. [2007]. It is also consistent with measurements of the dayside meridional winds from Pioneer Venus which indicate the horizontal divergence (converging air mass) of the meridional flow is greatest between 50 and $60^{\circ}$ [Limaye, 2007]. Poleward of $60^{\circ}$, the vortex "barrier" and decreasing sunlight would contribute to a negative latitudinal gradient in $\mathrm{CO}$, as observed. In addition, the fact that we observe the $\mathrm{CO}$ gradient at $35 \mathrm{~km}$, which is a proxy for the return branch of the Hadley cell, implies the vertical extent of the cell(s) is at least $40 \mathrm{~km}$.

[35] Acknowledgments. I would like to thank Emmanuel Marcq for his discussions of $\mathrm{CO}$ and his work with VIRTIS-H spectra and its findings. We would also like to thank Frank Mills and Robert Carlson for their discussions on this subject. This work was made possible from funding given by the United Kingdom Science Technology Facilities Council, as well as the continued support of CNES and ASI

\section{References}

Allen, D., and J. Crawford (1984), Cloud structure on the dark side of Venus, Nature, 307, 222-224, doi:10.1038/307222a0.

Baines, K., S. Sushil Atreya, R. Carlson, D. Crisp, P. Drossart, V. Formisano, S. Limaye, W. Markiewicz, and G. Piccioni (2006), To the depths of Venus: Exploring the deep atmosphere and surface of our sister world with Venus Express, Planet. Space Sci., 54, 1263-1278, doi:10.1016/ j.pss.2006.04.034

Bezard, B., C. de Bergh, D. Crisp, and J. Maillard (1990), The deep atmosphere of Venus revealed by high-resolution nightside spectra, Nature, 345, 508-511, doi:10.1038/345508a0.

Carlson, R., K. Baines, T. Encrenaz, F. Taylor, P. Drossart, L. Kamp, J. Pollack, E. Lellouch, and A. Collard (1991), Galileo infrared imaging 
spectroscopy measurements at Venus, Science, 253, 1541-1548, doi:10.1126/science.253.5027.1541.

Collard, A. (1993), Thermal emission from the nightside of Venus, D.Phil thesis, Univ. of Oxford, UK.

Collard, A., F. Taylor, S. Calcutt, R. Carlson, L. Kamp, and K. Baines (1993), Latitudinal distribution of carbon monoxide in the deep atmosphere of Venus, Planet. Space Sci., 41(7), 487-494.

Coradini, A., et al. (1998), VIRTIS: An imaging spectrometer for the Rosetta mission, Planet. Space Sci., 46(9-10), 1291-1304.

Counselman, C., S. Gourevitch, R. King, G. Loriot, and E. Ginsberg (1980), Zonal and meridional circulation of the lower atmosphere of Venus determined by radio interferometry, J. Geophys. Res., 85, 80268030, doi:10.1029/JA085iA13p08026.

Delaye, C., J. Hartmann, and J. Taine (1989), Calculated tabulations of $\mathrm{H}_{2} \mathrm{O}$ line broadening by $\mathrm{H}_{2} \mathrm{O}, \mathrm{N}_{2}, \mathrm{O}_{2}$, and $\mathrm{CO}_{2}$ at high temperature, Appl. Opt., 28(23), 5080-5087.

Drossart, P., et al. (2007), Scientific goals for the observation of Venus by VIRTIS on ESA/Venus Express mission, Planet. Space Sci., 55, 16531672, doi:10.1016/j.pss.2007.01.003.

Fegley, B. J., M. Y. Zolotov, and K. Lodders (1997), The oxidation state of the lower atmosphere and surface of Venus, Planet. Space Sci., 125, 416-439.

Gierasch, P. (1975), Meridional circulation and the maintenance of the Venus atmospheric rotation, J. Atmos. Sci., 32, 1038-1044, doi:10.1175/ 1520-0469(1975)032<1038:MCATMO>2.0.CO;2

Hong, Y., and B. Fegley (1997), Formation of carbonyl sulphide (OCS) from carbon monoxide and sulphur vapour and applications to Venus, Icarus, 130, 495-504, doi:10.1006/icar.1997.5824.

Huebner, W. F., J. J. Keady, and S. P. Lyon (1992), Solar photon rates for planetary atmospheres and atmospheric pollutants, Astrophys. Space Sci. 195, 1-294, doi:10.1007/BF00644558.

Irwin, P., P. Parrish, T. Fouchet, S. Calcutt, F. Taylor, A. Simon-Miller, and A. Nixon (2004), Retrievals of Jovian tropospheric phosphine from Cassini/CIRS, Icarus, 172, 37-49, doi:10.1016/j.icarus.2003.09.027.

Irwin, P. G. J., N. Teanby, R. de Kok, L. Fletcher, C. Howett, C. C. C. Tsang, C. F. Wilson, S. B. Calcutt, C. Nixon, and P. Parrish (2008a), The NEMESIS planetary atmosphere radiative transfer and retrieval tool, J. Quant. Spectrosc. Radiat. Transf., 109, 1136-1150, doi:10.1016/ j.jqsrt.2007.11.006.

Irwin, P. G. J., R. de Kok, A. Negrão, C. C. C. Tsang, C. F. Wilson, P. Drossart, G. Piccioni, D. Grassi, and F. W. Taylor (2008b), Spatial variability of carbon monoxide in Venus' mesosphere from Venus Express/VIRTIS Visible and Infrared Thermal Imaging Spectrometer measurements, J. Geophys. Res., 113, E00B01, doi:10.1029/ 2008JE003093.

Kamp, L., F. Taylor, and S. Calcutt (1988), Structure of Venus's atmosphere from modelling of night-side infrared spectra, Nature, 336, 360-362, doi: $10.1038 / 336360 \mathrm{a} 0$.

Karaiskou, A. C., C. Vallance, V. Papadakis, I. M. Vardavas, and T. P. Rakitzis (2004), Absolute absorption cross-section measurements of $\mathrm{CO}_{2}$ in the ultraviolet from 200 to $206 \mathrm{~nm}$ at 295 and $373 \mathrm{~K}$, Chem Phys. Lett., 400, 30-34.

Krasnopolsky, V. A. (2007), Chemical kinetic model for the lower atmosphere of Venus, Icarus, 191, 25-37, doi:10.1016/j.icarus.2007.04.028.

Lacis, A., and V. Oinas (1991), A description of the correlated k-distribution method for modeling non-grey gaseous absorption, thermal emission and multiple scattering in vertically inhomogeneous atmospheres, J. Geophys. Res., 96, 9027-9063, doi:10.1029/90JD01945.

Lee, C., S. Lewis, and P. Read (2007), Superrotation in a Venus general circulation model, J. Geophys. Res., 112, E04S11, doi:10.1029/ 2006JE002874

Limaye, S. (2007), Venus atmospheric circulation: Known and unknown, J. Geophys. Res., 112, E04S09, doi:10.1029/2006JE002814.
Marcq, E., B. Bezard, T. Encrenaz, and M. Birlan (2005), Latitudinal variations of $\mathrm{CO}$ and OCS in the lower atmosphere of Venus from nearinfrared nightside spectro-imaging, Icarus, 179, 375-386, doi:10.1016/ j.icarus.2005.06.018.

Marcq, E., T. Encrenaz, B. Bezard, and M. Birlan (2006), Remote sensing of Venus' lower atmosphere from ground-based spectroscopy: Latitudinal and vertical distribution of minor species, Planet. Space Sci., 54, 1360 1370, doi:10.1016/j.pss.2006.04.024.

Marcq, E., B. Bezard, P. Drossart, and G. Piccioni (2008), A latitudinal survey of $\mathrm{CO}, \mathrm{OCS}, \mathrm{H}_{2} \mathrm{O}$ and $\mathrm{SO}_{2}$ in the lower atmosphere of Venus: Spectroscopic studies using VIRTIS-H, J. Geophys. Res., doi:10.1029/ 2008JE003074, in press.

Oyama, V., G. Carle, F. Woeller, J. Pollack, R. Reynolds, and R. Craig (1980), Pioneer Venus gas chromatography of the lower atmosphere of Venus, J. Geophys. Res., 85, 7891 - 7902, doi:10.1029/JA085iA13p07891.

Palmer, K., and D. Williams (1975), Optical constants of sulfuric acid; Application to the clouds of Venus?, Appl. Opt., 14(1), 208-219.

Piccioni, G., et al. (2007), VIRTIS: The Visible and Infrared Thermal Imaging Spectrometer, ESA Spec. Publ. SP-1295, pp. 1-27, Eur. Space Agency, Paris.

Plass, G. N., G. W. Kattawar, and F. E. Catchings (1973), Matrix operator theory of radiative transfer: 1. Rayleigh scattering, Appl. Opt., 12, 314329.

Pollack, J., J. Dalton, D. Grinspoon, R. Wattson, R. Freedman, D. Crisp, D. Allen, B. Bezard, C. de Bergh, and L. Giver (1993), Near-infrared light from Venus' nightside: A spectroscopic analysis, Icarus, 103, 1-42, doi:10.1006/icar.1993.1055.

Rodgers, C. (1976), Retrieval of atmospheric temperature and composition from remote measurements of thermal radiation, Rev. Geophys., 14(4), 609-624, doi:10.1029/RG014i004p00609.

Seiff, A. (1983), Thermal structure of the atmosphere of Venus, in Venus, pp. 215-279, Univ. of Ariz., Tucson.

Shemansky, D. E. (1972), $\mathrm{CO}_{2}$ extinction coefficient $1700-3000 \AA$ J. Chem. Phys., 56, 1582-1587, doi:10.1063/1.1677408.

Taylor, F. (1995), Carbon monoxide in the deep atmosphere of Venus, $A d v$ Space Res., 16(6), 81-88, doi:10.1016/0273-1177(95)00253-B.

Taylor, F., D. Crisp, and B. Bezard (1997), Near-infrared sounding of the lower atmosphere of Venus, in Venus II: Geology, Geophysics, Atmosphere, and Solar Wind Environment, pp. 325-351, Univ. of Ariz. Press, Tucson.

Tonkov, M., N. Filippov, V. Bertsev, J. Bouanich, V.-T. Nguyen, C. Brodbeck, J. Hartmann, C. Boulet, and F. Thibault (1996), Measurements and empirical modeling of pure $\mathrm{CO}_{2}$ absorption in the $2.3 \mu \mathrm{m}$ region at room temperature: Far wings, allowed and collision- induced bands, Appl. Opt. 35(24), 4863-4870.

Tsang, C. C. C., P. G. J. Irwin, F. W. Taylor, and C. F. Wilson (2008), A correlated- $k$ model of radiative transfer in the near infrared windows of Venus, J. Quant. Spectrosc. Radiat. Transf., 109, 1118-1135, doi:10.1016/ j.jqsrt.2007.12.008

Von Zahn, U., S. Kumar, H. Niemann, and R. Prinn (1983), Composition of the Venus atmosphere, in Venus, pp. 299-430, Univ. of Ariz., Tucson.

B. Bezard and P. Drossart, LESIA, Observatoire de Paris, 5 place Jules Janssen, F-92195 Meudon, France.

S. Calcutt, R. de Kok, P. G. J. Irwin, F. W. Taylor, C. C. C. Tsang, and C. F. Wilson, Atmospheric, Oceanic and Planetary Physics, Clarendon Laboratory, Department of Physics, University of Oxford, Parks Road, Oxford OX1 3BH, UK. (con@atm.ox.ac.uk)

C. Lee, Geophysics and Planetary Sciences, California Institute of Technology, MC 150-21, Pasadena, CA 91125, USA. Italy. 